\title{
A simple method for simultaneous RP-HPLC determination of indolic compounds related to bacterial biosynthesis of indole-3-acetic acid
}

\author{
Michał Szkop • Wiesław Bielawski
}

Received: 26 August 2012/ Accepted: 18 October 2012/Published online: 31 October 2012

(C) The Author(s) 2012. This article is published with open access at Springerlink.com

\begin{abstract}
In this short technical report, we present a fast and simple procedure for sample preparation and a single-run Reversed Phase High Performance Liquid Chromatography (RP-HPLC) determination of seven indoles (indole-3-acetic acid, indole-3-acetamide, indole-3-acetonitrile, indole-3-ethanol, indole-3-lactic acid, tryptamine and tryptophan) in bacterial culture supernatants. The separation of the analytes, after a single centrifugal filtration clean-up step, was performed using a gradient elution on a symmetry $\mathrm{C} 8$ column followed by fluorimetric detection $\left(\lambda_{\mathrm{ex}}=280 / \lambda_{\mathrm{em}}=350 \mathrm{~nm}\right)$. The calibration curves were linear for all of the studied compounds over the concentration range of $0.0625-125$ $\mu \mathrm{g} \mathrm{mL}^{-1}\left(r^{2} \geq 0.998\right)$ and the limits of detection were below $0.015 \mu \mathrm{g} \mathrm{mL}^{-1}$. The applicability of the method was confirmed by analysis of Pseudomonas putida culture supernatants.
\end{abstract}

Keywords HPLC · Indolic compounds · IAA biosynthesis

M. Szkop $(\bowtie) \cdot$ W. Bielawski

Department of Biochemistry, Faculty of Agriculture and Biology, Warsaw University of Life SciencesSGGW, Nowoursynowska 159, 02-776 Warsaw, Poland e-mail: michal_szkop@sggw.pl

\section{Introduction}

Indole-3-acetic acid (IAA) is the most abundant naturally occurring auxin, which is a class of phytohormones implicated in the regulation of plant growth and development. In addition to plants, diverse species of soil and plant-associated bacteria can also produce IAA. Through the identification of bacterial genes and enzyme activities and the detection of indolic intermediates in bacterial culture supernatants, the existence of five different IAA biosynthesis routes has been determined with tryptophan (Trp) as a precursor: the indole-3-pyruvate (IPyA), indole-3-acetamide (IAM), tryptamine (TAM), indole-3-acetonitrile (IAN) and the Trp side chain oxidase pathways (Fig. 1; described in Carreno-Lopez et al. 2000; Spaepen et al. 2007). Additionally, it was observed that IAA produced by bacteria via distinct pathways may differentially affect plant growth. While IAA biosynthesized by beneficial bacteria designated as PGPR via the IPyA intermediate stimulated root proliferation and growth, IAA produced by phytopathogenic bacteria via the IAM intermediate induced galls and tumors formation in plants (Lambrecht et al. 2000). These findings suggest that there is a link between the IAA biosynthetic pathway used by a given bacterial strain and the host plant phenotype. It is therefore important not only to verify the ability of a particular strain of bacteria to produce IAA but also to investigate the biosynthetic route of this compound through, together with above mentioned approaches, determination of other 


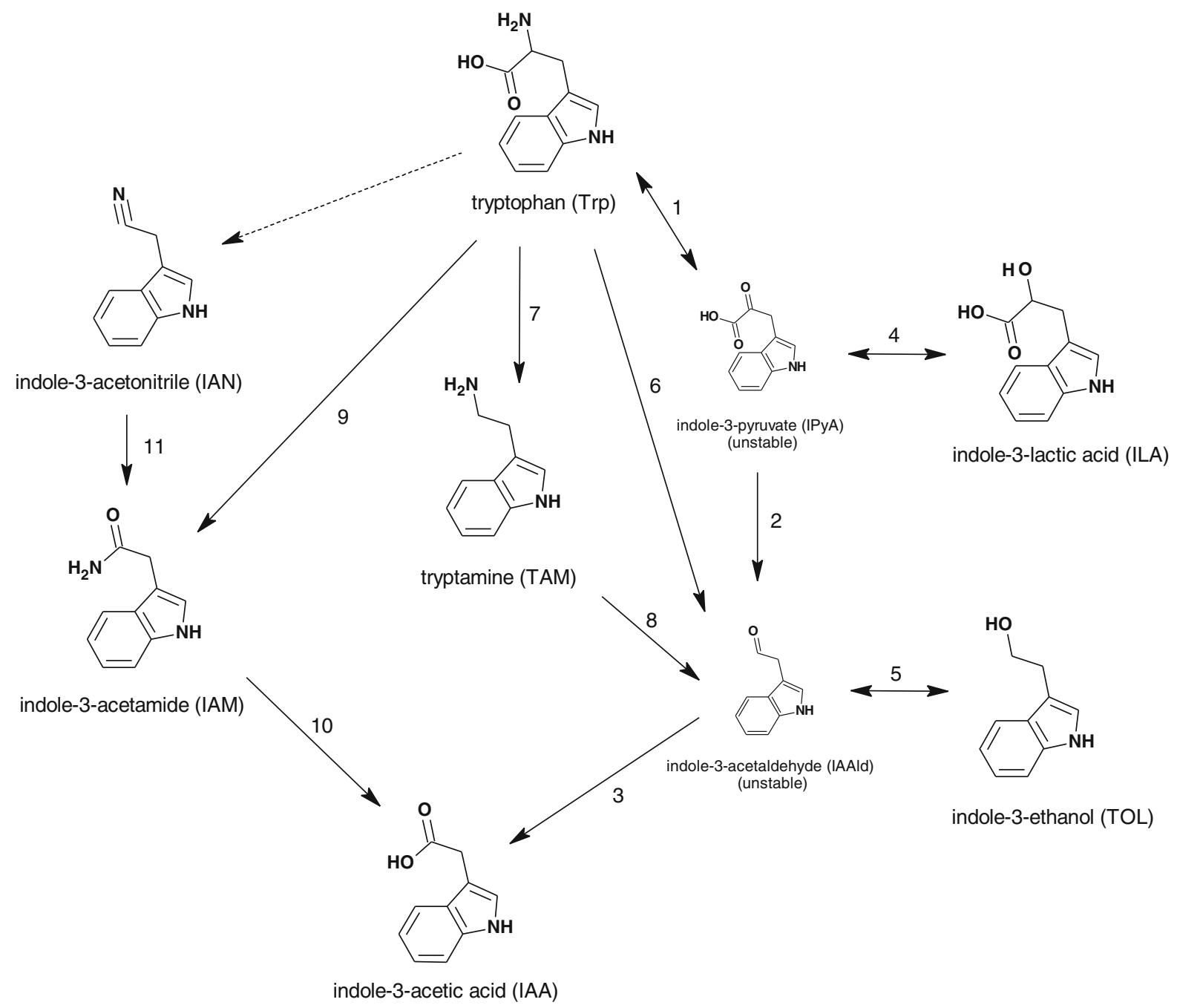

Fig. 1 Simplified diagram of Trp-dependent pathways for IAA biosynthesis in bacteria (compiled from Carreno-Lopez et al. 2000; Spaepen et al. 2007). (1) Aromatic amino acid aminotransferase; (2) IPyA decarboxylase; (3) IAAld dehydrogenase;

3-substituted indoles in the bacterial culture supernatant.

Among the available methods to determine IAA and related compounds, spectrophotometric (Akbari et al. 2007; Karnwal 2009; Sahasrabudhe 2011), thin layer chromatography (TLC) (Hartmann et al. 1983; Robinson et al. 1998; Swain et al. 2007) and HPLC assays are used most frequently. Spectrophotometric methods, which are based on the reaction of indoles with the Salkowski reagent and compare the color development of the reaction mixture with an appropriate reference, are nonspecific and provide only
(4) ILA dehydrogenase; (5) TOL dehydrogenase; (6) Trp sidechain-oxidase; (7) Trp decarboxylase; (8) TAM oxidase; (9) Trp 2-mono-oxygenase; (10) IAM hydrolase; and (11) nitrilase

quantitative determination of the total indoles content, rather than each of the analytes individually (Glickmann and Dessaux 1995). TLC methods, on the other hand, are used only for qualitative analysis. For both qualitative and quantitative determination of IAA and related 3-substituted indoles, several HPLC methods have been developed. However, these methods are complex and time- and reagent-consuming. First, sample preparation consists of several steps involving the repeated organic solvent extraction of an acidified bacterial culture supernatant (Garcia-Tabares et al. 1987; Sergeeva et al. 2007; Khakipour et al. 2008; Fedorov et al. 2010). It is 
worth noting that the extraction of TAM and indole-3ethanol (TOL) from acidic solutions is difficult, and these compounds have been independently extracted from neutral or basic solutions (Crozier et al. 1988; Furukawa et al. 1996; Carreno-Lopez et al. 2000). Second, for HPLC separation of the studied group of indolic compounds, two independent runs with two different sets of eluents have been conducted (Manulis et al. 1994; Carreno-Lopez et al. 2000; Reineke et al. 2008).

Thus, the aim of the present study was to develop a fast, simple, and reliable method for the simultaneous preparation and a single-run RP-HPLC determination of indolic compounds related to bacterial IAA production. In our study, we included IAA (product), Trp (precursor) and all five known and stable intermediates of IAA biosynthesis: IAM, IAN, indole-3-lactic acid (ILA), TAM and TOL. ILA and TOL are products of the enzymatic reduction of IPyA and indole-3acetaldehyde (IAAld), respectively. These latter two compounds are unstable and do not accumulate in bacterial cultures (Carreno-Lopez et al. 2000).

\section{Experimental}

Materials and reagents

Indole-3-acetic acid and $L$-tryptophan were purchased from Roth (Karlsruhe, Germany). Indole-3-acetamide, indole-3-acetonitrile, tryptamine, $D L$-indole-3-lactic acid, indole-3-ethanol and 3-kDa cut-off membrane centrifugal filters (Amicon Ultra $0.5 \mathrm{ml}$ centrifugal filters Z677094) were obtained from Sigma-Aldrich Inc. (St. Louis, MO, USA). HPLC-grade acetonitrile and methanol were purchased from POCH SA (Gliwice, Poland). All aqueous solutions were prepared using ultra-pure Milli-Q water.

Preparation of calibration curves and spike recovery analysis

The standard stock solutions $\left(15 \mathrm{mg} \mathrm{mL}^{-1}\right)$ of IAA, IAM, IAN, ILA, TAM and TOL were prepared in methanol. The standard Trp stock solution $\left(15 \mathrm{mg} \mathrm{mL}^{-1}\right)$ was prepared in water. A series $(n=13)$ of working solutions for each standard, ranging in concentration from 0.0625 to $125 \mu \mathrm{g} \mathrm{mL}^{-1}$, were prepared by appropriate dilution of the stock solution with methanol. All standard solutions were analyzed in triplicate. Calibration curves were constructed by performing a linear regression analysis of the peak area versus the analyte concentration. The limit of detection of each analyte was calculated from the chromatograms at a signal-to-noise ratio of 3 .

To determine the recovery of the studied indolic compounds from bacterial broth during sample preparation, standards were spiked into sterile King B liquid medium (King et al. 1954) at three different concentrations. Bacterial broth was processed with the sample preparation procedure described below.

Bacterial strain and culture conditions

Pseudomonas putida strain A, used in this study, was obtained from the collection of the Department of Biochemistry, SGGW, and was identified using the ribotyping method by Blirt S.A. DNA (Gdańsk, Poland). The 16S rRNA gene sequence of this strain is deposited in the DDBJ database under accession number AB667903. The bacteria were cultivated for $72 \mathrm{~h}$ in King B liquid medium with 0.5, 1.0, 2.0, 3.5 and $5.0 \mathrm{mM}$ Trp supplementation. Bacterial cultures were then centrifuged, and the bacterial culture supernatants were processed with the sample preparation procedure described below.

Sample preparation

Sample preparation consisted of a single centrifugal filtration step using 3-kDa cut-off membrane centrifugal filters. For this purpose, $0.5 \mathrm{~mL}$ of bacterial culture supernatants or spiked sterile bacterial broths were transferred to the sample chamber of a $0.5 \mathrm{~mL}$ centrifugal filter tube and centrifuged at $14,000 \times g$ (relative centrifugal force) at $4{ }^{\circ} \mathrm{C}$ for $30 \mathrm{~min}$. The filtrates were directly analyzed by HPLC.

Instrumentation and chromatographic conditions

The HPLC system was composed of a binary pump (Model 1525, Waters Corporation, Milford, MA, USA), a fluorimetric detector (Model 474, Waters), an autosampler (Model 717plus, Waters) and a personal computer with Breeze data acquisition and integration software (Waters). Chromatographic separations were performed at ambient temperature on a C8 column (Symmetry $4.6 \times 150 \mathrm{~mm}, 5 \mu \mathrm{m}$, Waters) fitted with a C8 guard column (Symmetry 


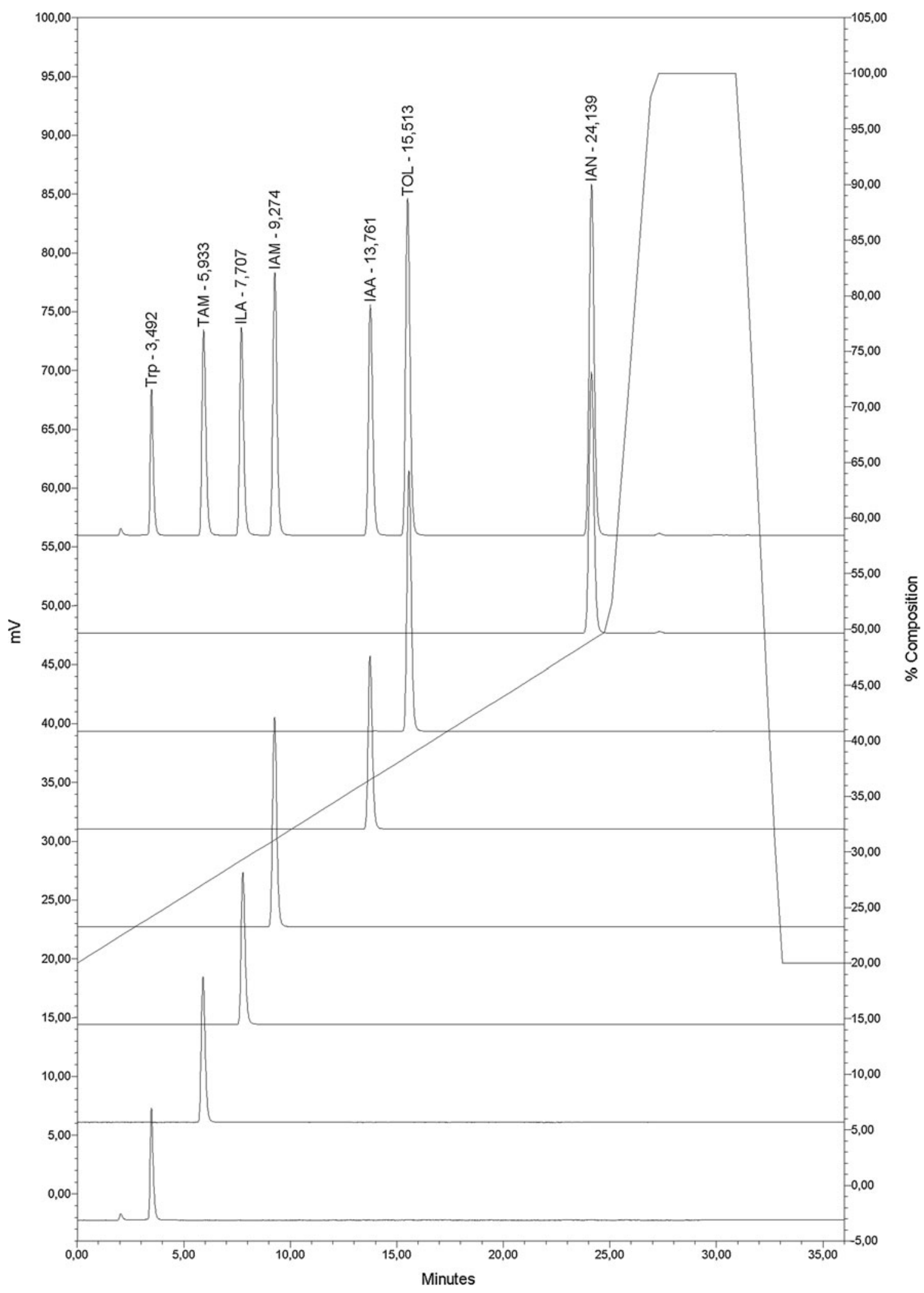


Fig. 2 Representative chromatograms from the separation of indolic standards. Chromatogram on the top shows the separation of a mixture of all indolic standards (each at a concentration of $\left.125 \mu \mathrm{g} \mathrm{mL}^{-1}\right)$. Chromatograms from top to bottom show separation of each of the indolic standards $\left(100 \mu \mathrm{g} \mathrm{mL}^{-1}\right)$ separately. Solid line represents the gradient profile

$3.9 \times 20 \mathrm{~mm}, 5 \mu \mathrm{m}$, Waters) using gradient elution. Eluent A consisted of $2.5: 97.5 \%(\mathrm{v} / \mathrm{v})$ acetic acid : $\mathrm{H}_{2} \mathrm{O}, \mathrm{pH} 3.8$ (the $\mathrm{pH}$ was adjusted by addition of $1 \mathrm{~mol}$ $\left.\mathrm{L}^{-1} \mathrm{KOH}\right)$ and eluent $\mathrm{B}$ consisted of $80: 20 \%(\mathrm{v} / \mathrm{v})$ acetonitrile : $\mathrm{H}_{2} \mathrm{O}$. The mobile phase started with eluent $\mathrm{A}$ : eluent B at $80: 20 \%$, changing to $50: 50 \%$, $0: 100 \%$ and $80: 20 \%$ in 25,31 and $33 \mathrm{~min}$, respectively. The total run time was $36 \mathrm{~min}$. The flow rate of the mobile phase was $1 \mathrm{~mL} \mathrm{~min}{ }^{-1}$, the injection volumes were $20 \mu \mathrm{L}$, and the fluorimetric detector was set to excitation and emission wavelengths of 280 and $350 \mathrm{~nm}$, respectively.

\section{Results and discussion}

Considering that the studied group of indoles possess acidic (IAA, ILA), amphoteric (Trp), basic (TAM) or essentially neutral (IAN, IAM, TOL) characters and that the $\mathrm{pH}$ of the mobile phase is an important factor influencing retention time and peak shape of ionizable compounds (Espinosa et al. 2002; Chandrul and Srivastava 2010), we tested mobile phases with different $\mathrm{pHs}$, in the range of 2.5 to 7.5 , with gradient or isocratic elution to determine the optimal
Fig. 3 Calibration curves (analyte concentration vs peak area) for studied indolic compounds. Each data point represents the mean $\pm \mathrm{SD}$ of three determinations

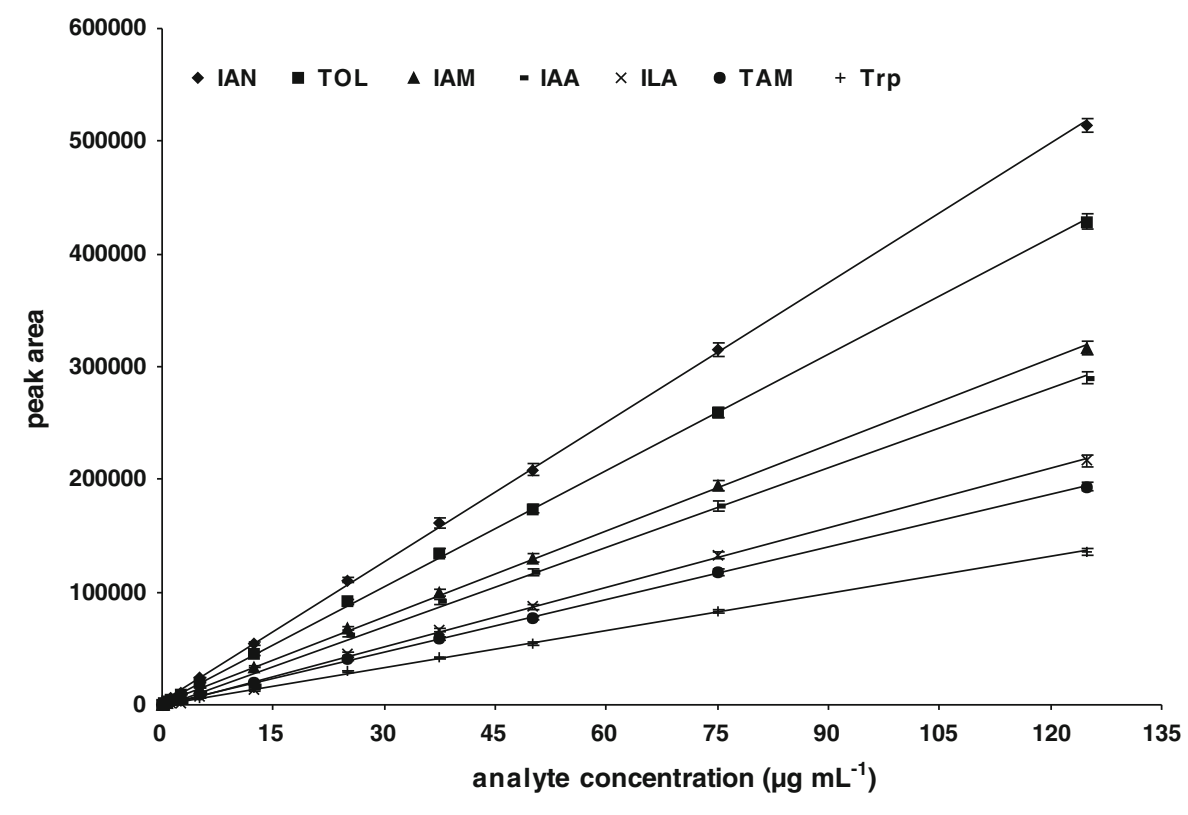

Table 1 Calibration curves parameters and the limits of detection of studied indolic compounds

\begin{tabular}{lllll}
\hline Compound & $\begin{array}{l}\text { Retention time } \\
(\mathrm{min})\end{array}$ & $\begin{array}{l}\text { The linear regression } \\
\text { equation }\end{array}$ & $\begin{array}{l}\text { Coefficient of } \\
\text { determination }\left(r^{2}\right)\end{array}$ & $\begin{array}{l}\text { Limit of detection } \\
\left(\mu \mathrm{g} \mathrm{mL} \mathrm{mL}^{-1}\right)\end{array}$ \\
\hline Trp & $3.5 \pm 0.04$ & $\mathrm{y}=1090.1 \mathrm{x}+469.0$ & 0.9997 & 0.0141 \\
TAM & $5.9 \pm 0.04$ & $\mathrm{y}=1547.4 \mathrm{x}+495.1$ & 0.9998 & 0.0099 \\
ILA & $7.7 \pm 0.06$ & $\mathrm{y}=1751.9 \mathrm{x}-1044.8$ & 0.9984 & 0.0096 \\
IAM & $9.3 \pm 0.07$ & $\mathrm{y}=2548.4 \mathrm{x}+1442.3$ & 0.9996 & 0.0079 \\
IAA & $13.8 \pm 0.09$ & $\mathrm{y}=2346.1 \mathrm{x}-1116.3$ & 0.9980 & 0.0089 \\
TOL & $15.5 \pm 0.10$ & $\mathrm{y}=3437.4 \mathrm{x}+1618.7$ & 0.9997 & 0.0062 \\
IAN & $24.1 \pm 0.10$ & $\mathrm{y}=4132.5 \mathrm{x}+2080.0$ & 0.9997 & 0.0043 \\
\hline
\end{tabular}


Table 2 Recoveries of the indolic compounds from the spiked King B liquid medium $(n=4)$

\begin{tabular}{|c|c|c|c|}
\hline Compound & $\begin{array}{l}\text { Amount added } \\
\left(\mu \mathrm{g} \mathrm{mL} L^{-1}\right)\end{array}$ & $\begin{array}{l}\text { Amount found } \\
\left(\mu \mathrm{g} \mathrm{mL}^{-1}\right)\end{array}$ & $\begin{array}{l}\text { Recovery } \\
(\%)\end{array}$ \\
\hline \multirow[t]{3}{*}{ Trp } & 0.50 & 0.49 & $98.83 \pm 2.1$ \\
\hline & 10.00 & 10.47 & $104.67 \pm 1.9$ \\
\hline & 125.00 & 121.81 & $97.45 \pm 1.6$ \\
\hline \multirow[t]{3}{*}{ TAM } & 0.50 & 0.47 & $94.24 \pm 3.2$ \\
\hline & 10.00 & 9.94 & $99.44 \pm 2.0$ \\
\hline & 125.00 & 122.98 & $98.38 \pm 3.5$ \\
\hline \multirow[t]{3}{*}{ ILA } & 0.50 & 0.48 & $96.08 \pm 4.5$ \\
\hline & 10.00 & 9.97 & $99.74 \pm 2.1$ \\
\hline & 125.00 & 125.32 & $100.26 \pm 2.4$ \\
\hline \multirow[t]{3}{*}{ IAM } & 0.50 & 0.48 & $96.70 \pm 4.6$ \\
\hline & 10.00 & 10.24 & $102.44 \pm 2.3$ \\
\hline & 125.00 & 124.71 & $99.77 \pm 1.9$ \\
\hline \multirow[t]{3}{*}{ IAA } & 0.50 & 0.50 & $100.30 \pm 4.1$ \\
\hline & 10.00 & 9.98 & $99.84 \pm 2.8$ \\
\hline & 125.00 & 126.75 & $101.4 \pm 2.7$ \\
\hline \multirow[t]{3}{*}{ TOL } & 0.50 & 0.47 & $94.09 \pm 4.2$ \\
\hline & 10.00 & 9.99 & $99.87 \pm 3.1$ \\
\hline & 125.00 & 123.28 & $98.62 \pm 2.6$ \\
\hline \multirow[t]{3}{*}{ IAN } & 0.50 & 0.46 & $92.43 \pm 4.0$ \\
\hline & 10.00 & 9.48 & $94.77 \pm 2.3$ \\
\hline & 125.00 & 119.41 & $95.53 \pm 2.9$ \\
\hline
\end{tabular}

chromatography conditions. The best conditions for separation were obtained using $2.5: 97.5 \%(\mathrm{v} / \mathrm{v})$ acetic acid : $\mathrm{H}_{2} \mathrm{O}$, pH 3.8 and $80: 20 \%$ (v/v) acetonitrile : $\mathrm{H}_{2} \mathrm{O}$ with gradient elution. Under these conditions, peaks were sharp, well resolved, and symmetrical for all analytes. The retention times were approximately $3.5,5.9,7.7,9.3,13.8,15.5$ and $24.1 \mathrm{~min}$ for Trp, TAM, ILA, IAM, IAA, TOL and IAN, respectively (Fig. 2). The linearity of the dependence of the detector response on the analyte concentration was evaluated by triplicate analysis of thirteen standard solutions containing $0.0625-125 \mu \mathrm{g} \mathrm{mL}^{-1}$ of each indolic compound (Fig. 3). All the resulting calibration curves were characterized by a high coefficient of determination $\left(r^{2} \geq 0.998\right)$, indicating the broad linear working range of the method. The limits of detection for all studied analytes were below $0.015 \mu \mathrm{g} \mathrm{mL}^{-1}$ (Table 1). These results, together with the fact that the concentrations of indolic compounds accumulating in bacterial cultures typically reaches from a few to several dozens of $\mu \mathrm{g} \mathrm{mL}^{-1}$ (Ahmad et al.
Fig. 4 Representative chromatograms obtained during the analysis of indolic compounds in $P$. putida strain A culture supernatants. Chromatogram on the top shows the separation of $P$. putida strain A culture supernatant after $72 \mathrm{~h}$ of growth in King B medium supplemented with $3.5 \mathrm{mM}$ Trp. Chromatogram on the bottom shows the separation of a sterile King B medium supplemented with $3.5 \mathrm{mM}$ Trp (control)

2005; Khakipour et al. 2008; Chaiharn and Lumyong 2011), indicate that no additional enrichment of the biological sample is required. Therefore, instead of time- and reagent-consuming organic solvent extraction, we utilized a single centrifugal filtration step for sample preparation. This simple step eliminates high molecular weight $(>3 \mathrm{kDa})$ contaminants that damage the column, gives excellent recoveries at all levels of analyte loading for all studied indolic compounds (Table 2) and provides adequate sample purity with low levels of interference (see chromatograms in Fig. 4).

Finally, to verify the reliability of the established method, we analyzed culture supernatants of $P$. putida after $72 \mathrm{~h}$ of growth in King B medium supplemented with different concentration of Trp. In the tested samples, we identified 3 compounds that had retention times corresponding to those of ILA, IAA and IAM (Fig. 4). Quantitative analysis revealed that ILA was the most abundant compound (2.6-34.0 $\mu \mathrm{g} \mathrm{mL}^{-1}$ ), followed by IAA $\left(0.7-10.3 \mu \mathrm{g} \mathrm{mL}^{-1}\right)$, with IAM present in very small amounts $\left(0-0.4 \mu \mathrm{g} \mathrm{mL}^{-1}\right)$. The level of biosynthesis of these compounds was positively correlated with Trp concentration (Fig. 5). These results are consistent with other reports on the effect of exogenously supplied Trp on the level of IAA (or other indoles) biosynthesis by bacteria (Carreno-Lopez et al. 2000; Sergeeva et al. 2007; Spaepen et al. 2007), which shows the consistency of the method. Moreover, detection of small amounts of IAM suggest that there is direct conversion of this compound to IAA, and that the studied P. putida strain operates via IAM pathway. Accumulation of high amounts of ILA (together with no detection of TOL) indicates, on the other hand, that Trp is efficiently metabolized via transamination, but resulting IPyA (ILA) is not further converted to IAA. These observation agrees with our previous findings concerning studied strain of bacteria, from which we isolated two aromatic amino acid aminotransferase isozymes with high activities toward Trp (Szkop et al. 2012). 


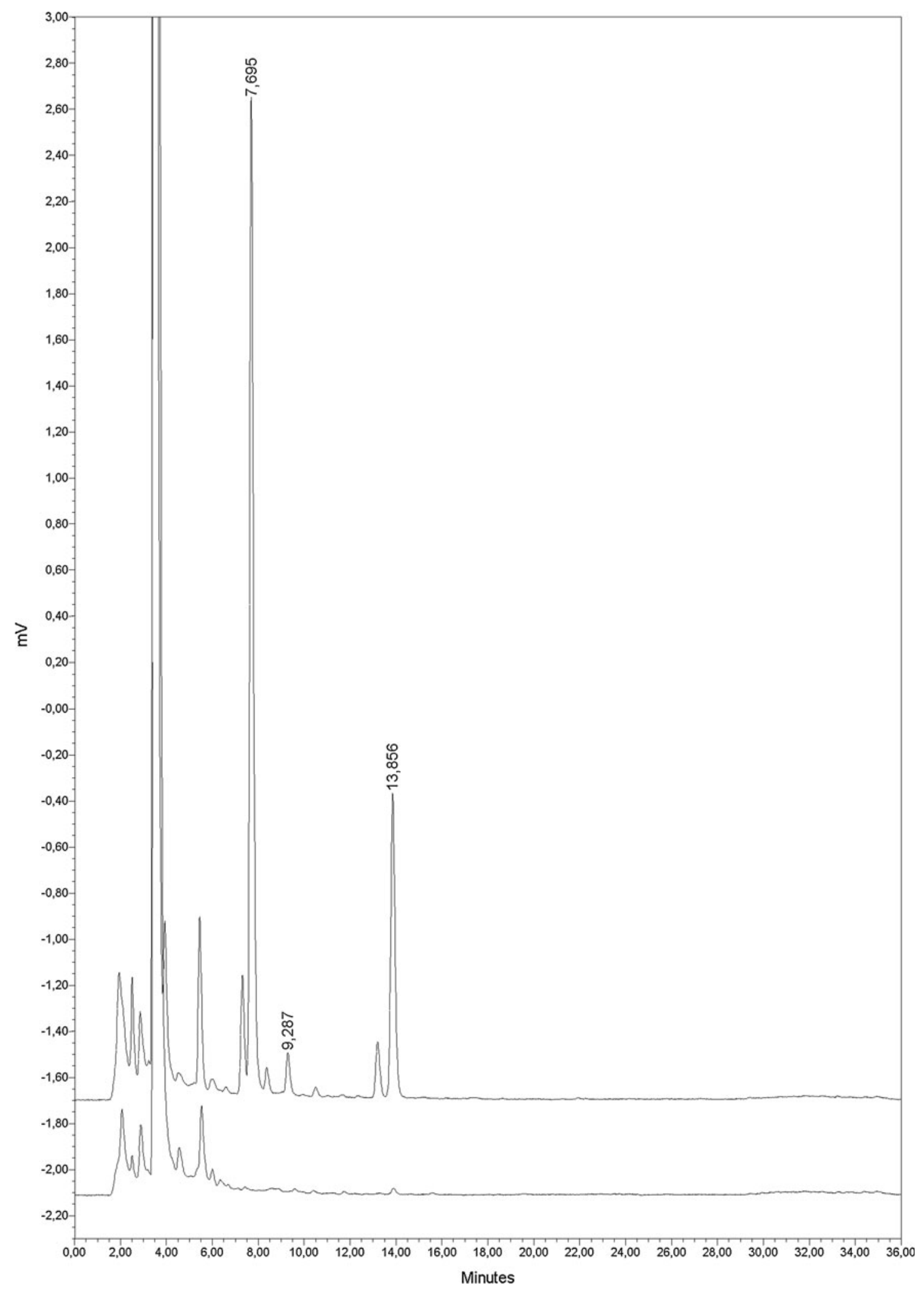


Fig. 5 Effect of Trp concentration on ILA, IAA and IAM biosynthesis by P. putida strain A. Each data point represents the mean $\pm \mathrm{SD}$ of three determinations

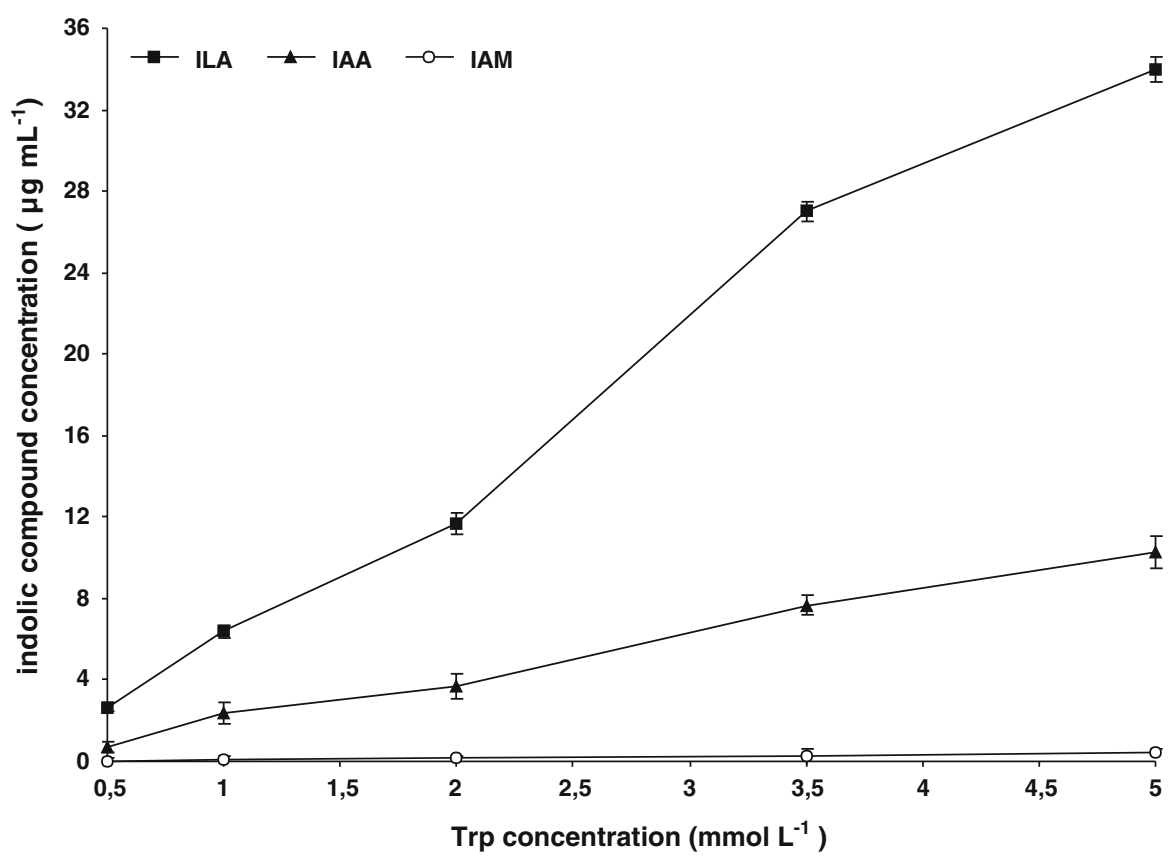

\section{Summary}

The method described here, compared to those applied previously, significantly simplifies both the sample preparation and HPLC analysis of IAA and related indolic compounds in bacterial culture supernatants. First, a simple one-step sample preparation procedure, taking advantage of the fluorescent properties of indoles, provides adequate sample purity, selectivity and sensitivity. Second, the developed and optimized chromatographic conditions allow for determination of a investigated range of indolic compounds in a single chromatographic run using one set of eluents. Therefore, the presented method should be especially useful for routine assays.

Acknowledgments This work was supported by the Polish Ministry of Science and Higher Education (Grant No. N N310 304639).

Open Access This article is distributed under the terms of the Creative Commons Attribution License which permits any use, distribution, and reproduction in any medium, provided the original author(s) and the source are credited.

\section{References}

Ahmad F, Ahmad I, Khan MS (2005) Indole acetic acid production by the indigenous isolates of Azotobacter and fluorescent Pseudomonas in the presence and absence of Tryptophan. Turk J Biol 29:29-34

Akbari GA, Arab SM, Alikhani HA, Allahdadi I and Arzanesh MH (2007) Isolation and selection of indigenous Azospirillum spp. and the IAA of superior strains effects on wheat roots. World J Agric Sci 3(4):523-529

Carreno-Lopez R, Campos-Reales N, Elmerich C, Baca BE (2000) Physiological evidence for differently regulated tryptophandependent pathways for indole-3-acetic acid synthesis in Azospirillum brasilense. Mol Gen Genet 264(4):521-530

Chaiharn M, Lumyong S (2011) Screening and optimization of indole-3-acetic acid production and phosphate solubilization from rhizobacteria aimed at improving plant growth. Curr Microbiol 62(1):173-181

Chandrul KK, Srivastava B (2010) A process of method development: a chromatographic approach. J Chem Pharm Res 2(2):519-545

Crozier A, Arruda P, Jasmim JM, Monteiro AM, Sandberg G (1988) Analysis of indole-3-acetic acid and related indoles in culture medium from Azospirillum lipoferum and Azospirillum brasilense. Appl Environ Microbiol 54(11):2833-2837

Espinosa S, Bosch E, Rosés M (2002) Retention of ionizable compounds on HPLC. 12. The properties of liquid chromatography buffers in acetonitrile-water mobile phases that influence HPLC retention. Anal Chem 74(15):3809-3818

Fedorov DN, Doronina NV, Trotsenko YA (2010) Cloning and characterization of indolepyruvate decarboxylase from Methylobacterium extorquens AM1. Biochemistry (Mosc) 75(12):1435-1443

Furukawa T, Koga J, Adachi T, Kishi K, Syono K (1996) Efficient conversion of L-tryptophan to indole-3-acetic acid and/or tryptophol by some species of Rhizoctonia. Plant Cell Physiol 37(7):899-905

Garcia-Tabares F, Herraiz-Tomico T, Amat-Guerri F, Garcia Bilbao JL (1987) Production of 3-indoleacetic acid and 
3-indolelactic acid in Azotobacter vinelandii cultures supplemented with tryptophan. Appl Microbiol Biotechnol 25:502-506

Glickmann E, Dessaux Y (1995) A critical examination of the specificity of the salkowski reagent for indolic compounds produced by phytopathogenic bacteria. Appl Environ Microbiol 61:793-796

Hartmann A, Singh M, Klingmuller W (1983) Isolation and characterization of Azospirillum mutants excreting high amounts of indoleacetic acid. Can J Microbiol 29:916-923

Karnwal A (2009) Production of indole acetic acid by fluorescent Pseudomonas in the presence Of L-tryptophan and rice root exudates. J Plant Pathol 91(1):61-63

Khakipour N, Khavazi K, Mojallali H, Pazira E, Asadirahmani H (2008) Production of auxin hormone by fluorescent pseudomonads. American-Eurasian J Agric \& Environ Sci 4(6): 687-692

King EO, Ward MK, Raney DE (1954) Two simple media for the demonstration of pyocyanin and fuorescein. J Lab Clin Med 44:301-302

Lambrecht M, Okon Y, Vande Broek A, Vanderleyden J (2000) Indole-3-actic acid: a reciprocal signaling molecule in bacteria-plant interaction. Trends Microbiol 8(7):298-300

Manulis S, Shafrir H, Epstein E, Lichter A, Barash I (1994) Biosynthesis of indole-3-acetic acid via the indole-3-acetamide pathway in Streptomyces spp. Microbiology 140:1045-1050
Reineke G, Heinze B, Schirawski J, Buettner H, Kahmann R, Basse CW (2008) Indole-3-acetic acid (IAA) biosynthesis in the smut fungus Ustilago maydis and its relevance for increased IAA levels in infected tissue and host tumour formation. Mol Plant Pathol 9(3):339-355

Robinson M, Riov J, Sharon A (1998) Indole-3-acetic acid biosynthesis in Colletotrichum gloeosporioides f. sp. Aeschynomene. Appl Environ Microbiol 64(12):5030-5032

Sahasrabudhe MM (2011) Screening of rhizobia for indole acetic acid production. Ann Biol Res 2(4):460-468

Sergeeva E, Hirkala DLM, Nelson LM (2007) Production of indole3-acetic acid, aromatic amino acid aminotransferase activities and plant growth promotion by Pantoea agglomerans rhizosphere isolates. Plant Soil 297(1-2):1-13

Spaepen S, Vanderleyden J, Remans R (2007) Indole-3-acetic acid in microbal and microorganism-plant signaling. FEMS Microbiol Rev 31:425-448

Swain MR, Naskar SK, Ray RC (2007) Indole-3-acetic acid production and effect on sprouting of yam (Dioscorea rotundata L.) minisetts by Bacillus subtilis isolated from culturable cowdung microflora. Pol J Microbiol 56(2):103-110

Szkop M, Sikora P, Orzechowski S (2012) A novel, simple, and sensitive colorimetric method to determine aromatic amino acid aminotransferase activity using the salkowski reagent. Folia Microbiol 57(1):1-4 